\title{
Efficient Transmission of 'Candidatus Phytoplasma prunorum' Is Delayed by Eight Months Due to a Long Latency in Its Host-Alternating Vector
}

\author{
Gaël Thébaud, Michel Yvon, Rémi Alary, Nicolas Sauvion, and Gérard Labonne
}

First, second, fourth, and fifth authors: Institut National de la Recherche Agronomique (INRA), UMR BGPI, CIRAD TA A-54/K, Campus international de Baillarguet, 34398 Montpellier cedex 5, France; and third author: INRA, UMR DAP, 2 Place Viala, 34060 Montpellier cedex 1, France.

Accepted for publication 5 December 2008.

\begin{abstract}
Thébaud, G., Yvon, M., Alary, R., Sauvion, N., and Labonne, G. 2009. Efficient transmission of 'Candidatus Phytoplasma prunorum' is delayed by eight months due to a long latency in its host-alternating vector. Phytopathology 99:265-273.

Understanding at which spatiotemporal scale a disease causes significant secondary spread has both theoretical and practical implications. We investigated this issue in the case of European stone fruit yellows (ESFY), a quarantine vector-borne phytoplasma disease of Prunus trees. Our work was focused on the processes underlying disease spread: the interplay between the life cycles of the pathogen ('Candidatus Phytoplasma prunorum') and of the vector (Cacopsylla pruni). We demonstrated experimentally that $C$. pruni has only one generation per year and we

immature and mature C. pruni were hardly infectious (0.6\%) despite effective phytoplasma acquisition and multiplication. We demonstrated that most immature vectors born on infected plants reach their maximum phytoplasma load $\left(10^{7}\right.$ genomes per insect) only after migrating to conifers and that, after a life-long retention of the phytoplasma, their transmission efficiency was very high $(60 \%)$ at the end of winter (when they migrate back to their Prunus host). Thus, most transmissions occur only after an effective latency of 8 months, following vector migrations and overwintering on conifers in mountainous regions. From this transmission cycle, we can infer that local secondary spread of ESFY in apricot orchards is marginal, and recommend that disease management strategies take more into account the processes occurring at a regional scale, including the role of wild Prunus spp. in ESFY epidemics.
\end{abstract} showed that, at least in southeastern France, $C$. pruni migrates between conifers in mountainous regions (where it overwinters) and Prunus spp. at lower altitude (where it breeds). In acquisition-inoculation experiments performed with C. pruni over its period of presence on Prunus spp., both
Additional keywords: blackthorn, monocyclic, polycyclic, polyetic, primary infection, Prunus spinosa, psyllid, real-time PCR.
The concepts of primary and secondary infections have both theoretical and practical implications in epidemiology. Primary infections originate from outside a given host population, whereas secondary infections originate from within it. On this basis, diseases are commonly classified as monocyclic (where only primary infections occur during one growing season of the host) or polycyclic (where an infected plant can give rise to further infections within the same growing season) $(3,42)$. Both types exhibit different spatiotemporal patterns of spread $(3,15,39)$ that have to be taken into account in the definition of relevant control strategies. Vector-borne diseases are generally polycyclic within a year and sometimes between years; thus, in perennial crops, the roguing of infected plants is often suggested to prevent an exponential increase in disease incidence. Implementing or enforcing this control method can be economically and socially costly. Thus, it is desirable to make sure that roguing is likely to be efficient, which requires identifying the spatial and temporal scales at which secondary transmissions can occur. However, such crucial biological information is lacking for a number of diseases, including European stone fruit yellows (ESFY).

ESFY is a quarantine disease affecting mainly apricot (Prunus armeniaca) and Japanese plum ( $P$. salicina) orchards in Europe

Corresponding author: G. Thébaud; E-mail address: thebaud@supagro.inra.fr

doi:10.1094/PHYTO-99-3-0265

This article is in the public domain and not copyrightable. It may be freely reprinted with customary crediting of the source. The American Phytopathological Society, 2009.
(23). The disease can be graft- or vector-transmitted to most Prunus species $(5,27)$; however, different species, cultivars, and rootstocks have a different susceptibility $(4,19,40)$. ESFY is caused by a phytoplasma (28) for which the name 'Candidatus Phytoplasma prunorum' has been proposed (36). The disease is characterized by various physiological disorders $(9,27)$ : short internodes, early leafing, leaf rolling, and chlorosis, late and scarce flowering, premature fruit fall, increased frost sensitivity and, depending on weather conditions, sudden or slow tree death. Because of the obvious economic consequences of these symptoms, ESFY is recorded as a quarantine disease by the main national and international organizations in charge of plant protection.

Up to now, only one insect species has been identified as a vector for ' $\mathrm{Ca}$. P. prunorum': Cacopsylla pruni (8). In the scarce entomological records concerning this psyllid, it is described as a European and Middle-Asiatic univoltine species: after winter, the mature (dark-winged) adults breed on blackthorn ( $P$. spinosa) where five larval instars can be observed, and the subsequent immature (light-colored) adults disappear from Prunus spp. at the beginning of the summer; during the rest of the year this species is reported mainly on conifers $(16,21,31)$. The temporal dynamics of $C$. pruni population density has been assessed on different Prunus hosts, showing the synchronous presence of the psyllid on different Prunus spp. from the beginning of February to the end of June or July in all the French areas where $C$. pruni has been searched (20). This multihost multisite field survey and measures of mortality and fecundity in experimental conditions (5) provided a congruent hierarchy of host preference for $C$. pruni: blackthorn $>$ plum (European, Japanese, myrobalan) $>>$ apricot $>$ 
peach $>$ almond $>>$ cherry. In contrast, nothing is known about the long period spent by $C$. pruni on conifers, and the biological cycle of the species has never been completed in controlled conditions; thus, the hypotheses regarding $C$. pruni life cycle still have to be tested.

During recent years, several aspects of the transmission properties of ESFY by its vector have been revealed. ESFY-positive $C$. pruni have been found in several countries: Italy (8), France (18), Spain (22), Switzerland (33), Czech Republic (12), and BosniaHerzegovina (10). ESFY-positive and infectious $C$. pruni have been detected among both immature and mature adults sampled from natural populations (6). It has been shown that ' $\mathrm{Ca}$. P. prunorum' is transmitted in a persistent manner, with minimum acquisition, latency, and inoculation periods of 2 to 4 days, 2 to 3 weeks, and 1 to 2 days, respectively (7). Although these are minimum times and not median times, such biological features generally lead to local secondary spread and polycyclic diseases (or polyetic, for long latent periods in perennial plants). However, three crucial points for the epidemiology of ESFY remain unclear: (i) the transmission efficiency of immature vectors before leaving their Prunus hosts, (ii) the persistence and infectivity of the phytoplasma until the end of the period spent by the vector on conifers, and (iii) whether a healthy adult can acquire the phytoplasma after migrating back on Prunus spp. and transmit it before the end of its life. These three unresolved points determine whether transmission from infected to healthy plants occurs mainly within or between years; depending on the distances involved in C. pruni biannual host alternations, these points may also define the basic spatial scale of ESFY epidemics, which is of major concern to control strategies.

In the work presented here, our aim was to improve the knowledge of ESFY epidemiology by confronting the biology of the vector $C$. pruni with the biology of ' $\mathrm{Ca}$. P. prunorum' transmission. More specifically, we demonstrate experimentally the life cycle of $C$. pruni, and assess the possibility for the psyllid to complete the acquisition-latency-inoculation sequence within each period spent on Prunus spp. by comparing transmission experiments and phytoplasma load in the vector throughout its lifetime.

\section{MATERIALS AND METHODS}

Insect collection and rearing. Adult $C$. pruni were collected from plants with a $0.5-\mathrm{m}^{2}$ white beating tray. For the acquisitioninoculation tests, mature adults were gathered between February and May from blackthorn (P. spinosa) mainly on the 800-m-high Larzac plateau (55 km northwest of Montpellier, France). For the study of $C$. pruni life cycle, blackthorn bushes in the plain to the north of Montpellier (site 3 ) were used as a source of mature adults for caging experiments and for weekly surveys of adult $C$. pruni density in comparison with a conifer forest located on the 700-mhigh Séranne mountain (site 1, $35 \mathrm{~km}$ northwest of Montpellier). For density surveys, the sampling effort was standardized on conifers (20 minutes) and on blackthorn (20 plants). The insects were reared on $P$. marianna under fine-meshed sleeve cages in climatic chambers $\left(23^{\circ} \mathrm{C}, 16\right.$-h day length, relative humidity $\left.\geq 80 \%\right)$.

Demonstration of $\boldsymbol{C}$. pruni life cycle. To test whether some $C$. pruni overwinter within blackthorn bushes, part of a bush was enclosed under two fine-meshed cages in December 2002, after the departure of the immature adults but before the arrival of the mature insects. Each cage contained two sticky blue traps (attractive to $C$. pruni) and covered $3.24 \mathrm{~m}^{2}$ of ground. In spring 2003, the traps were checked under the cages after the arrival of $C$. pruni on the neighboring blackthorn bushes. The experiment was replicated over the next winter. In addition, a survey was carried out from 2003 to 2007 in the whole Languedoc area in order to identify natural overwintering sites for $C$. pruni. The resulting count data were analyzed using a generalized linear model (GLM) accounting for overdispersed Poisson data (2) as implemented in the dispmod $\mathrm{R}$ package.

To complete $C$. pruni life cycle, we reared mature insects in the laboratory. Their eggs hatched and, after five larval instars, they developed into immature adults, 2,935 of which were transferred in June and August 2004 on conifers at three sites: on Abies sp. in site 1, on Picea abies at an altitude of $1,260 \mathrm{~m}$ in the Aigoual massif (site 2), and on Pinus halepensis in site 3. The psyllids were maintained until February inside fine-meshed sleeve cages enclosing conifer shoots. Within each site, the standard deviation (SD) survival rates between cages was compared with the expected SD under the hypothesis of binomial distribution of survival rates within each cage. Survival was analyzed with a GLM accounting for overdispersed binomial data (43) as implemented in the dispmod $\mathrm{R}$ package.

Experimental acquisition-inoculation of ' $\mathrm{Ca}$. $\mathrm{P}$. prunorum' by $\boldsymbol{C}$. pruni. To investigate the acquisition-latency-inoculation sequence, 10 Prunus marianna plants were graft-inoculated with 'Ca. P. prunorum' strain PO00. At least 18 months later, mature C. pruni collected on blackthorn were reared on these ESFYinfected (tested positive using polymerase chain reaction [PCR]) plants. On some plants, the mature insects were removed 20 days after laying eggs, and the nymphs and immature adults obtained from their progeny were kept on the infected plant. A sample of immature adults was transferred to the experimental overwintering sites, subsequently maturing into adults with a known history of exposure to the phytoplasma. Mature adults (and their progeny) reared on four healthy plants were used as controls.

After an acquisition access period (AAP) of 1 to 20 days (mature adults) or 16 to 65 days (immature adults), a sample of the psyllids was conserved at $-80^{\circ} \mathrm{C}$ and the remainder of the experimental population was set on healthy test plants (young $P$. marianna cuttings) in groups of 2 to 15 individuals, or individually at the end of the overwintering experiment. After a subsequent 20-day inoculation access period (IAP), the surviving psyllids were recovered and conserved at $-80^{\circ} \mathrm{C}$ until DNA extraction. Phytoplasma presence was assessed using PCR for 475 C. pruni (including 330 controls), and the transmission tests involved 6,633 C. pruni (including 3,408 controls). The test plants were sprayed with an insecticide and incubated in an insect-proof greenhouse or in climatic chambers. Because of the slow phytoplasma multiplication, the plants were tested for ESFY infection at least 7 months later, using PCR. The experiments were replicated on a smaller scale with other field isolates and other source species ( $P$. armeniaca and $P$. salicina) in order to check the generality of the results regarding ' $\mathrm{Ca}$. P. prunorum' isolate and Prunus species. Fisher's exact test (13) was used to compare proportions. All reported confidence intervals (CI) are exact $95 \%$ CI (1) as implemented in the binGroup R package.

DNA extraction and ' $\boldsymbol{C a}$. P. prunorum' detection. Total DNA was extracted as previously described from $0.5 \mathrm{~g}$ of plant phloem (24) and whole insects (26). The reproducibility of insect DNA extraction was assessed from 10 individual $C$. pruni with the PicoGreen dsDNA quantification kit (Molecular Probes) using $\lambda$ DNA as a standard; after excitation at $480 \mathrm{~nm}$, the fluorescence emission was measured at $526 \mathrm{~nm}$ with an LS50B fluorescence spectrophotometer (Applied Biosystems). Plant and insect DNA was stored at $-20^{\circ} \mathrm{C}$ after resuspension in 100 and $30 \mu \mathrm{l}$, respectively, of water treated with diethylpyrocarbonate (DEPC). The primer pair ESFYf/r (Table 1) was used to specifically detect ' $C a$. P. prunorum' in plants and individual insects (38). Each amplification reaction was performed in $20 \mu \mathrm{l}$ containing $1 \mu \mathrm{l}$ of template DNA, $1 \times$ PCR buffer, and 0.5 units of Taq DNA polymerase (Invitrogen), $1.5 \mathrm{mM} \mathrm{MgCl} 2,125 \mu \mathrm{M}$ each dNTP, and $0.35 \mu \mathrm{M}$ each primer. The PCR conditions were as follows: denaturation at $94^{\circ} \mathrm{C}$ for $1 \mathrm{~min}$; followed by 20 cycles at $94^{\circ} \mathrm{C}$ for $30 \mathrm{~s}, 65^{\circ} \mathrm{C}$ for $20 \mathrm{~s}$, and $72^{\circ} \mathrm{C}$ for $45 \mathrm{~s}$; and then 20 cycles at $94^{\circ} \mathrm{C}$ for $30 \mathrm{~s}, 62^{\circ} \mathrm{C}$ for $20 \mathrm{~s}$, and $72^{\circ} \mathrm{C}$ for $45 \mathrm{~s}$. 
'Ca. P. prunorum' quantification. The timing of ' $\mathrm{Ca}$. P. prunorum' accumulation in its vector was investigated through estimating the number of copies of ' $C a$. P. prunorum' genome present in 139 individual psyllids (including 13 controls) sampled during the acquisition-inoculation experiment after several combinations of AAP and IAP. To this aim, we developed a new real-time PCR assay based on TaqMan technology. Using Clustal W v1.83 (41), we identified fragments in ' $\mathrm{Ca}$. P. prunorum' rDNA region with enough divergence across taxa to provide a good level of specificity in the detection of the phytoplasma. ' $\mathrm{Ca}$. P. prunorum' $16 \mathrm{~S}$ rDNA region was screened with the software Primer Express v1.5 (Applied Biosystems) to design the primers ECAQf/r (delimiting a 108-bp fragment) and the probe ECAQp (Fig. 1). Extensive BLAST searches in GenBank confirmed that ECAQf/p/r were highly unlikely to detect DNA from organisms outside the $16 \mathrm{SrX}$ phytoplasma group (Fig. 1). The primers $\mathrm{CPf} / \mathrm{r}$ and probe $\mathrm{CPp}$ complementary to a 92-bp fragment of $C$. pruni $18 \mathrm{~S}$ rDNA (Table 1) were used as a control of DNA extraction in insects. The probes ECAQp and CPp were labeled at the $5^{\prime}$ end with the fluorescent dyes VIC and FAM, respectively, and at the $3^{\prime}$ end with the quencher TAMRA (Applied Biosystems).

We used the following real-time PCR conditions: $5 \mu \mathrm{l}$ of plant or insect total DNA extract, $0.2 \mu \mathrm{M}(\mathrm{CPf} / \mathrm{r})$ or $0.6 \mu \mathrm{M}(\mathrm{ECAQf} / \mathrm{r})$ each primer, $0.2 \mu \mathrm{M}(\mathrm{CPp})$ or $0.25 \mu \mathrm{M}$ (ECAQp) probe, adjusting the volume to $25 \mu \mathrm{l}$ with TaqMan Universal PCR Master Mix (Applied Biosystems), according to the manufacturer's instructions. An initial cycle of $2 \mathrm{~min}$ at $50^{\circ} \mathrm{C}$ and $10 \mathrm{~min}$ at $95^{\circ} \mathrm{C}$ was followed by 40 cycles alternating between $95^{\circ} \mathrm{C}$ for $15 \mathrm{~s}$ and $60^{\circ} \mathrm{C}$ for $1 \mathrm{~min}$. The analyses were performed in triplicates with an ABI Prism 7700 and the Sequence Detector software (v.1.9.1; Applied Biosystems). The number of phytoplasma genomes per insect $\left(N_{\mathrm{P}}\right)$ was estimated as $N_{\mathrm{P}}=a \times N_{\mathrm{T}} / 2=3.75 \times N_{\mathrm{T}}$, where $a$ is the overall dilution factor and $N_{\mathrm{T}} / 2$ is the number of phytoplasma genomes in the sample, because there are 2 rRNA operons per ' $\mathrm{Ca}$. P. prunorum' genome (25). The results were analyzed with the R statistical software (34).

\section{RESULTS}

Demonstration of $C$. pruni life cycle. No $C$. pruni were trapped in the blackthorn bushes caged during two consecutive winters whereas, at the end of each winter, mature $C$. pruni were found on the rest of the bush; in addition, during the survey carried out from 2003 to 2007, no C. pruni were found in winter on blackthorn bushes or in their immediate surroundings. Thus, it is at best infrequent and maybe impossible for $C$. pruni to overwinter within blackthorn bushes. Moreover, during the same survey (Table 2), only two overwintering $C$. pruni were found in the plain (in December, on Pinus halepensis), while their density was much higher $\left(P=1.7 \times 10^{-3}\right)$ on the nearby plateau and mountains on conifers of the genera Abies, Picea, or Pinus (but not Cedrus). Overall, the Larzac plateau and Aigoual massif had similar psyllid densities (Table 2), but the distribution of $C$. pruni was heterogeneous within each zone, with sites 1 and 2 consistently sheltering more individuals than their respective vicinities $(P=4.7 \times$ $10^{-13}$ ); even within site 1 and site $2, C$. pruni appeared to congregate in restricted parts of the forests (G. Labonne, personal observation).

Few insects survived until the end of the experimental overwintering, and survival was very irregular between cages (on average, 2.8 times more variable than expected if insect deaths were independent), indicating that individuals within a given cage share many risk factors, such as predators and pathogens; for example, entomopathogenic fungi killed many psyllids in both natural and caged populations at site 2 (Table 3). Survival in site 1 $(8.2 \%)$, at higher altitude, was significantly greater than in the other sites $(P=0.021)$. Survival on conifers in the plain (site 3$)$ was lower but $1.9 \%$ of the caged insects still managed to survive until the following year, contrasting with their quasi-absence in the field survey. The $136 \mathrm{C}$. pruni that survived the overwintering experiment at altitude were caged on P. marianna, where they laid eggs that developed normally into nymphs and immature adults, thus completing the experimental replication of $C$. pruni biological cycle.

In a $C$. pruni population density survey in spring 2004 (Fig. 2), the highest number of immature adults on $P$. spinosa in site 3 occurred in a narrow peak during the first 2 weeks of June, followed by a sudden drop and a complete absence after early July, defining a maximum 5-week-long period during which an immature adult might stay on its Prunus host. On conifers in site 1, the first $C$. pruni was collected in mid-June, and the highest density was reached in mid-July. Thus, the emigration period of the im-

TABLE 1. Primers and probes for the detection and quantification of 'Candidatus Phytoplasma prunorum' and Cacopsylla pruni targets

\begin{tabular}{ll}
\hline Oligonucleotide name & \multicolumn{1}{c}{ Sequence $\left(5^{\prime} \rightarrow 3^{\prime}\right)$} \\
\hline 'Ca. . prunorum' 16S rDNA & \\
ESFYf (forward) & CCATCATTTAGTTGGGCACT \\
ESFYr (reverse) & ATAGGCCCAAGCCATTATTG \\
ECAQf (forward) & AAACGACTGCTAAGACTGGATATGAA \\
ECAQp (probe) & VIC-CCCGCAAGGGTATGCTGAGAGATGG-TAMRA \\
ECAQr (reverse) & TTACCAACTAACTAATGTGCCGCA \\
C. pruni $18 \mathrm{~S}$ rDNA & \\
CPf (forward) & CAAGTACGTCCCCGTTGATCA \\
CPp (probe) & FAM-TTAGAGGTTCGAAGGCGATCAGATACCGC-TAMRA \\
CPr (reverse) & GCTGGCTGACATCGTTTATGG \\
\hline
\end{tabular}

\begin{tabular}{|c|c|c|}
\hline & ECAQf & ECAQp \\
\hline ESFY G1R $(X)$ & AAACGACTGCTAAGACTGGATATGAA & : CCCGC----AAGGGTATGCTGAGAGATGG GCT EGCGGCACATTAGTTAGTTGGTAA \\
\hline ESFY G2 (X) & $\ldots \ldots \ldots \ldots \ldots$ &.--- \\
\hline $\operatorname{AP} 15^{R}(X)$ & $\ldots \ldots \ldots G \ldots$ & $\ldots . .---$ \\
\hline $\operatorname{PD1R}(\mathrm{X})$ & $\ldots \ldots \ldots \ldots$. & $\ldots \ldots----$ \\
\hline SpaWB $(X)$ & $\ldots \ldots \ldots \ldots \ldots \ldots \ldots \ldots$ & $\ldots \ldots \ldots$ A........ \\
\hline BWB $(X)$ & $\ldots \ldots \mathrm{T} \ldots \ldots \ldots \ldots \ldots$ G. & .Т.----.А. $\ldots \ldots \ldots$ А. $\ldots \ldots \ldots \ldots \ldots$ \\
\hline OY-M (I) & $\ldots \ldots \ldots \ldots \ldots \ldots \ldots$ G $_{\text {G }}$ & 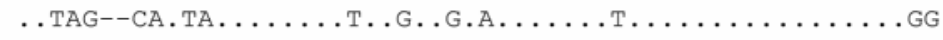 \\
\hline AlmWB (IX) & $\ldots$ AGT $\ldots \ldots \ldots \ldots \ldots$ G. & 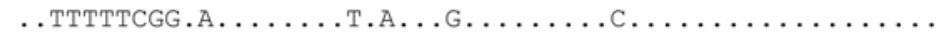 \\
\hline WX (III) & 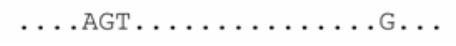 & T.TT.TTT-G.A.......AG. .G. \\
\hline
\end{tabular}

Fig. 1. Aligned 16S rDNA sequences for phytoplasma occurring in stone fruit trees or in the $16 \mathrm{SrX}$ group, showing the primers and probe (ECAQf/p/r) designed for the real-time polymerase chain reaction assay. 
mature adults from $P$. spinosa in the plain corresponded roughly to their arrival period on conifers $27 \mathrm{~km}$ away, after a gap of at least 2 weeks (Fig. 2).

Acquisition and inoculation of ' $\mathrm{Ca}$. P. prunorum' by $\mathrm{C}$. pruni. In the acquisition-inoculation experiments, the ESFY phytoplasma could be detected in $2.8 \%$ (CI: 1.2 to $5.2 \%$ ) of the control mature adults (overwintering on conifers), increasing to $85 \%$ (CI: 63.1 to $95.8 \%$ ) after only a 1-day AAP (Fig. 3A). However, most of them appeared to lose the phytoplasma when acquisition stopped, because only $25 \%$ of the insects were still ESFY-positive (highly significant difference: $P=3.3 \times 10^{-4}$ ) after subsequently feeding on a healthy plant until day 20 (Fig. 3A, solid arrow). After 2 to 20 days of AAP, $96 \%$ of the mature adults were ESFY-positive; likewise, all the tested immature adults were ESFY-positive after spending 30 days on infected plants (Fig. $3 \mathrm{~A})$; thus, phytoplasma ingestion is easy for both mature and immature $C$. pruni. The progeny of adults exposed to the phytoplasma for 1 and 20 days was ESFY-negative (0/40, CI: 0 to $8 \%$ ), showing no evidence of transovarial transmission of the phytoplasma (Fig. 3A).

For mature controls, transmission rate $(0.47 \%$; CI: 0 to $0.8 \%)$ was five times smaller than infection rate $\left(P=3.8 \times 10^{-4}\right)$. After acquisition on infected plants, almost all the insects were ESFYpositive (Fig. 3A); despite that, subsequent inoculations proved to be inefficient for all stages (Fig. 3B). In fact, the transmission rates after acquisition were not even significantly different from the respective controls (Fig. 3B, inset): of 900 immature insects, $0.56 \%$ (CI: 0.21 to $1.3 \%$ ) were infectious after an AAP of 16 to 37 days, of 2,315 immature insects, $0.65 \%$ (0.36 to $1.1 \%$ ) were infectious after an AAP of 1 to 20 days; in the linear model built to analyze these results, neither acquisition nor stage nor their interaction was significant $(0.13 \leq P \leq 0.37)$. There was no significant difference in the transmission efficiency between nymphs and immature adults (not shown). Among the insects that survived until the end of the experimental overwintering, 10 had been born on ESFY-infected plants (AAP: 57 to 65 days); $80 \%$ of them (Fig. 3A) were ESFY-positive (CI: 34 to $99 \%$ ) and, in striking contrast with all the other transmission rates, $60 \%$ of these insects (Fig. 3B) were infectious (CI: 28 to $85 \%$ ), indicating that transmission was efficient after a long latency and providing, in addition, a useful positive control for the whole acquisition-inoculation experiment. We found no indication of different transmission efficiency between source species or ' $\mathrm{C} a$. P. prunorum' isolates.

Quantification of ' $\boldsymbol{C} \boldsymbol{a}$. P. prunorum' in $\boldsymbol{C}$. pruni. The extraction yield varied little, producing very stable DNA concentrations (mean \pm SD: $246.3 \pm 6.17$ ng. $\mathrm{ml}^{-1}$ ). The standard curves (not shown) indicated that real-time amplification performed well, with a consistent and high PCR efficiency (95.4\% for ' $\mathrm{Ca}$. P. prunorum' and $98.2 \%$ for C. pruni).

For mature and immature $C$. pruni reared on ESFY-infected plants, phytoplasma load measured at any time between 1 and 65 days was significantly higher than phytoplasma load in the control groups; thus, both mature and immature vectors were able to ingest the phytoplasma, even after just 1 day of AAP (Fig. 4A). We built a series of nested models (not shown) relating the logarithm of the number of phytoplasma genomes to vector stage and AAP, and the best model had one slope for each stage (where

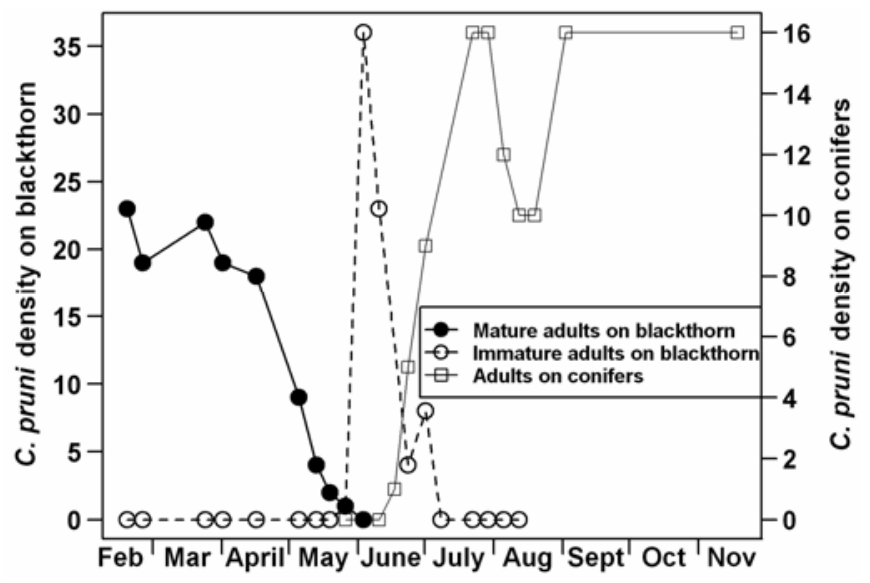

Fig. 2. Temporal dynamics of Cacopsylla pruni density on blackthorn (Prunus spinosa) and conifers. Numbers are standardized by the sampling effort (20 plants for blackthorn; 20 minutes for conifers).

TABLE 2. Occurrence and number of overwintering Cacopsylla pruni collected during surveys on conifers in the Languedoc area (20 minutes per sampling)

\begin{tabular}{|c|c|c|c|c|c|c|c|}
\hline Location (no. of sites) & Altitude (m) & Host plant & Occurrence $^{\mathrm{a}}$ & Total $^{\mathrm{b}}$ & Mean $^{\mathrm{c}}$ & $\mathrm{SD}^{\mathrm{d}}$ & Significance $^{\mathrm{e}}$ \\
\hline Aigoual massif (7) & $1,100-1,400$ & Abies alba, Picea abies, Pinus nigra & $22 / 26$ & 157 & 6.04 & 6.22 & - \\
\hline Others & & A. alba, P. abies & $5 / 9$ & 19 & 2.11 & 2.76 & $\mathrm{~B}_{1}$ \\
\hline Larzac plateau (13) & $550-800$ & P. nigra, $P$. sylvestris, Abies $\mathrm{sp}$. & $39 / 52$ & 267 & 5.14 & 5.17 & - \\
\hline Site 1 & 700 & Abies sp. & $31 / 32$ & 250 & 7.82 & 4.87 & $\mathrm{~A}_{2}$ \\
\hline Others & & P. nigra, $P$. sylvestris, Abies sp. & $8 / 20$ & 17 & 0.85 & 1.31 & $\mathrm{~B}_{2}$ \\
\hline Hérault plain (8) & $100-300$ & P. nigra, $P$. halepensis & $2 / 20$ & 2 & 0.10 & 0.31 & $\mathrm{C}$ \\
\hline
\end{tabular}

a Occurrence: (number of samplings in which at least one $C$. pruni was collected)/(total number of samplings).

b Total number of $C$. pruni individuals collected at each location.

${ }^{\mathrm{c}}$ Mean number of $C$. pruni individuals collected per 20-min sampling.

d Standard deviation.

${ }^{\mathrm{e}}$ Significance group $\left(-=\right.$ not tested): different letters stand for significantly different means (overdispersed Poisson generalized linear model; $5 \%$ level). $P\left(\mathrm{~A}_{1}=\right.$ $\left.\mathrm{A}_{2}\right)=0.85, P\left(\mathrm{~B}_{1}=\mathrm{B}_{2}\right)=0.10, P(\mathrm{~A}=\mathrm{B})=4.7 \times 10^{-13}, P(\mathrm{~B}=\mathrm{C})=1.7 \times 10^{-3}$.

TABLE 3. Survival of Cacopsylla pruni during experimental overwintering on conifers

\begin{tabular}{lccccccc}
\hline Location & Cages & Caged & Recovered & Survival $(\%)^{\text {Obs. SD }(\%)^{\mathrm{a}}}$ & ${\text { Exp. SD }(\%)^{\mathrm{b}}}^{\text {Significance }^{\mathrm{c}}}$ \\
\hline Site 1 (Séranne) & 43 & 1,380 & 113 & 8.19 & 14.7 & 4.45 & $\mathrm{~A}$ \\
Site 2 (Aigoual) & 30 & 920 & $11^{\mathrm{d}}$ & 1.20 & 4.57 & 1.88 \\
Site 3 (Montpellier) & 21 & 635 & 12 & 1.89 & 4.74 & $\mathrm{~B}$ \\
\hline
\end{tabular}

a Observed standard deviation (SD) of the survival rate between cages.

${ }^{\mathrm{b}}$ Expected SD under the assumption of binomial distribution of survival rates within each cage.

${ }^{\mathrm{c}}$ Significance group: different letters stand for significantly different means (overdispersed binomial generalized linear model; $\chi^{2}$ test at the $5 \%$ level). $P(\mathrm{~A}=\mathrm{B})=$ 0.021 .

$\mathrm{d}$ Many psyllids were killed by entomopathogenic fungi. 
only the slope for the immature insects was significantly different from $0 ; P=8.11 \times 10^{-14}$ ) and a common intercept. All points but one lied on the regression line fitted for the immature insects, which could also be extrapolated up to 85 days after acquisition start because this regression line was an excellent predictor of the overplotted phytoplasma load after an AAP of 65 days followed by 20 days of IAP on a healthy plant. Later on, there was no significant difference between 85,181 , and 325 days after acquisition start: there was a plateau at $\approx 10^{7}$ phytoplasma genomes per insect (Fig. 4B), and the insect with the highest number of phytoplasma genomes $\left(4.9 \times 10^{7}\right)$ was found at the end of the overwintering period ( 325 days after acquisition start).

The comparison between four AAP modalities observed 20 days after acquisition start unveils important characteristics of the phytoplasma-vector interaction (Fig. 5): after 20 days of AAP, immature insects harbored significantly more phytoplasmas than mature insects; in addition, phytoplasma load in mature insects was significantly higher after 20 days of AAP than after 1 day but not 2 days, indicating that, after at least a 2-day AAP, most $C$. pruni can keep a high phytoplasma load throughout the subsequent IAP. Where the AAP is followed by an IAP, the larger variance is noteworthy even if it is not statistically significant (Fig. 5); it can be explained by a decrease in phytoplasma load in some insects during the IAP. Finally, after a 20-day AAP, phytoplasma load was not significantly different between four males and nine females (not shown).

Phytoplasma multiplication can be inferred from the nature of the increase in phytoplasma load for the immature insects in continuous AAP, which is not linear but exponential (Fig. 4A). To test whether multiplication occurs in mature insects, we compared the distribution of the number of phytoplasma genomes just after an AAP of 2 to 20 days and after 20 to 30 days of subsequent IAP.

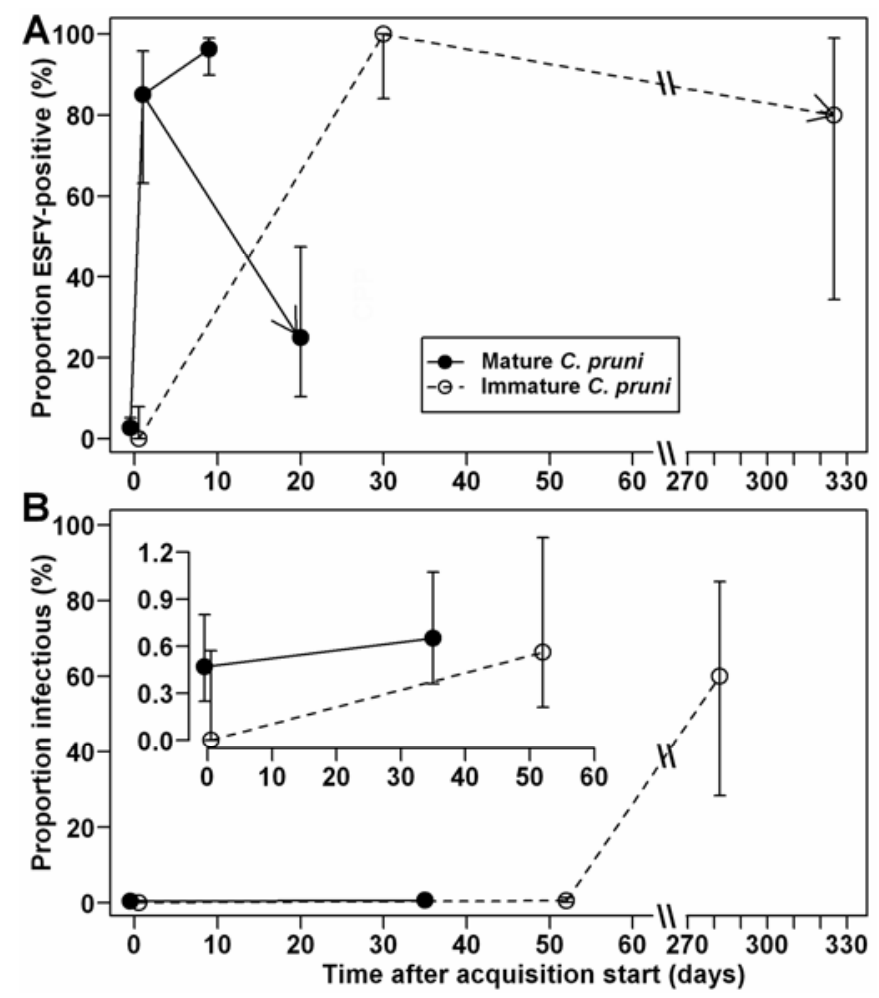

Fig. 3. Infection status of Cacopsylla pruni (mature and immature insects) in relation to the time after acquisition start. The bars define $95 \%$ confidence intervals, and the points after the temporal gap on the x-axis correspond to tests made after the experimental overwintering. A, Proportion of ESFYpositive C. pruni; each inoculation access period (IAP) following an acquisition access period is represented by an arrow which base and head corresponds to the beginning and end of the IAP, respectively. B, Proportion of infectious $C$. pruni. The inset is a close-up view of the low transmission rates.
There was no difference between the means of the two distributions but the variance was significantly higher after the IAP $(P=$ $3.6 \times 10^{-5}$; Ansari-Bradley test) because many individuals had extremely low or high phytoplasma loads (Fig. 6A). This experiment demonstrates that, after AAP, the phytoplasma disappears from some insects and multiplies in others. Just after a 1-day AAP, the distribution (not shown) matched the solid curve but, after a subsequent 19-day IAP (Fig. 6A, dashed line), most insects had lost the phytoplasma $\left(P=1.2 \times 10^{-3}\right.$; Mann-Whitney test $)$. Similarly, we compared the distribution of the number of phytoplasma genomes in immature insects at the end of a 65-day AAP and after 20 days of subsequent IAP (Fig. 6B); the mean phytoplasma load was significantly higher after the IAP $\left(P=2.4 \times 10^{-2}\right.$; Mann-Whitney test) and, despite the long AAP, the phytoplasma had disappeared from some insects, leading to a bimodal

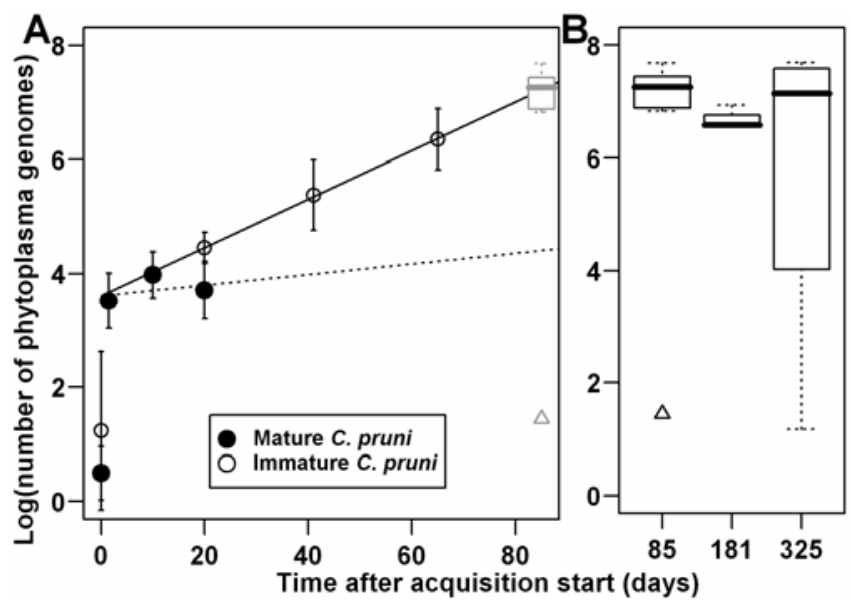

Fig. 4. Logarithm of the number of phytoplasma genomes per individual Cacopsylla pruni estimated by quantitative polymerase chain reaction at different times after acquisition start. A, Mean phytoplasma load and associated $95 \%$ confidence intervals for mature and immature vectors after continuous acquisition access period (AAP) on ESFY-infected plants. The solid and dotted lines represent the best-fitting linear models for immature and mature insects, respectively. Extrapolating the regression line for immature insects predicts phytoplasma load for a 65-day AAP followed by a 20-day inoculation access period (IAP) (distribution represented by the overplotted gray boxplot). B, Boxplot showing the plateau reached when the AAP is followed by a 20-day IAP or by an experimental overwintering period (140 and 244 days) on conifers; there is no statistically significant difference in the medians.

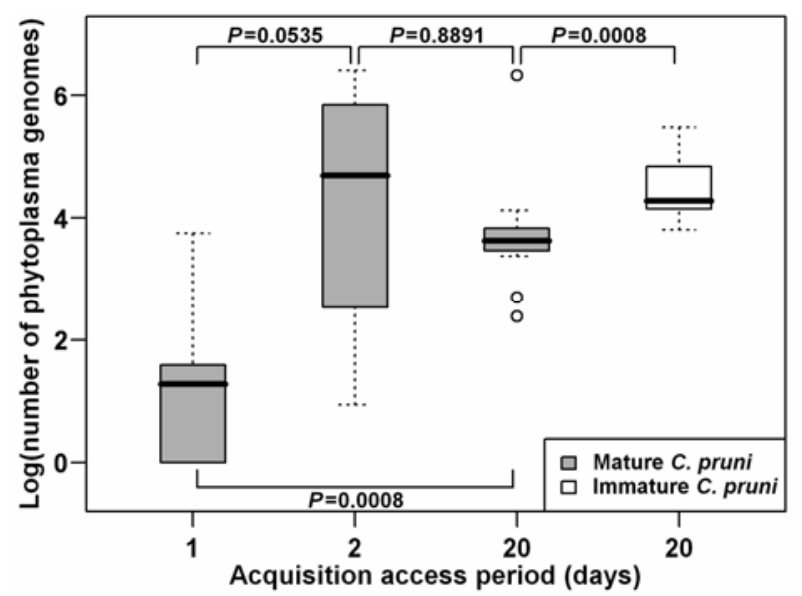

Fig. 5. Logarithm of the number of phytoplasma genomes per individual Cacopsylla pruni estimated by quantitative polymerase chain reaction 20 days after acquisition start. The $P$ values correspond to pairwise comparisons for the medians between groups with a different acquisition access period (MannWhitney tests, with Holm multiple testing correction). 
distribution. The same pattern was observed (Fig. 6B, dashed line) for the insects overwintering on conifers tested long after acquisition start (181 and 325 days; AAP: 41 and 65 days).

\section{DISCUSSION}

The goal of this work was to better understand the biological processes that determine the spatiotemporal scale at which secondary transmission of ESFY occurs. We established important features of the interactions between the transmission cycle of the phytoplasma and the life cycle of its vector (Fig. 7): we provided the first experimental demonstration of $C$. pruni life cycle, we showed that ' $C a$. P. prunorum' multiplies in both immature and
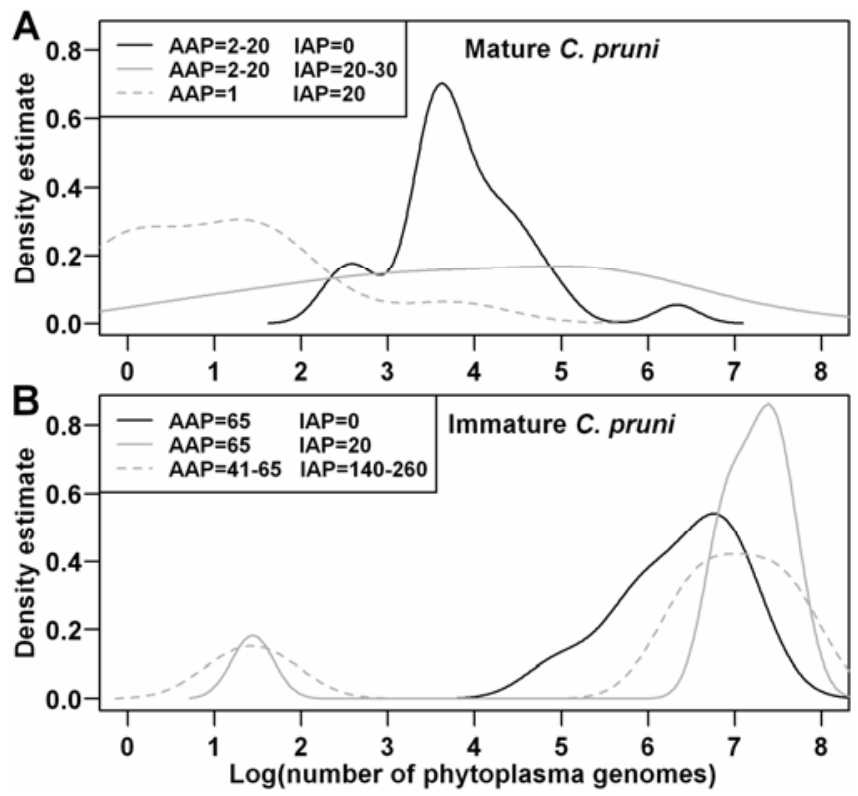

Fig. 6. Estimated distribution of the logarithm of the number of phytoplasma genomes per A, mature and $\mathbf{B}$, immature individual Cacopsylla pruni. Each line represents a different combination of acquisition access period (AAP) and inoculation access period (IAP). mature vectors, and we proved that the full acquisition-latencyinoculation sequence can be completed only by a few immature adults before emigrating from Prunus hosts and by very few, if any, mature adults before their death. In contrast, after acquisition by the immature vectors, ' $\mathrm{Ca}$. P. prunorum' can be conserved throughout the 8 months they spend on conifers (where phytoplasma load reaches a plateau) and can be transmitted very efficiently without additional acquisition when the vectors migrate back to Prunus hosts.

C. pruni biology. Our results on $C$. pruni life cycle validate previous assertions based on entomological observations (16,21, 31): $C$. pruni is a univoltine species breeding on Prunus spp. in spring and spending the rest of the year on conifers. However, contrasting with observations in the Czech Republic (21), we found no indication that $C$. pruni might overwinter within $P$. spinosa bushes: in winter, we could not find a single $C$. pruni in two caged blackthorn bushes or during intensive searches on Prunus spp. Indeed, it has been previously noticed that "caged insects die in the greenhouse when in nature the new adults are abandoning the primary hosts" (7). This period at the beginning of summer corresponded to a sharp drop in $C$. pruni population density on Prunus spp. (Fig. 2). We also documented a surprising feature of the overwintering sites: even if some individuals could survive an experimental host alternation in the plain (Table 3), $C$. pruni density on conifers in the plain next to blackthorn hedges was 8 to 80 times lower than in mountains several kilometers away from Prunus spp. (Table 2). Taken together, these lines of evidence show that host alternation is obligatory for $C$. pruni; in southeastern France, migrations occur between Prunus spp. and conifers over several kilometers, probably helped by the dominant winds blowing from the sea toward the mountains in summer and in the opposite direction in spring.

Characteristics of ' $\mathrm{Ca}$. P. prunorum' transmission by $\boldsymbol{C}$. pruni. Thanks to the breeding of $C$. pruni in seminatural conditions, we obtained, for the first time, several mature adults known to be born on ESFY-infected plants. This technical progress enabled us to unveil the interactions between the life cycle of the vector and the growth rate of the phytoplasma. As shown by PCR tests and phytoplasma quantification, both mature and immature vectors needed at least a 2-day AAP to conserve the acquired
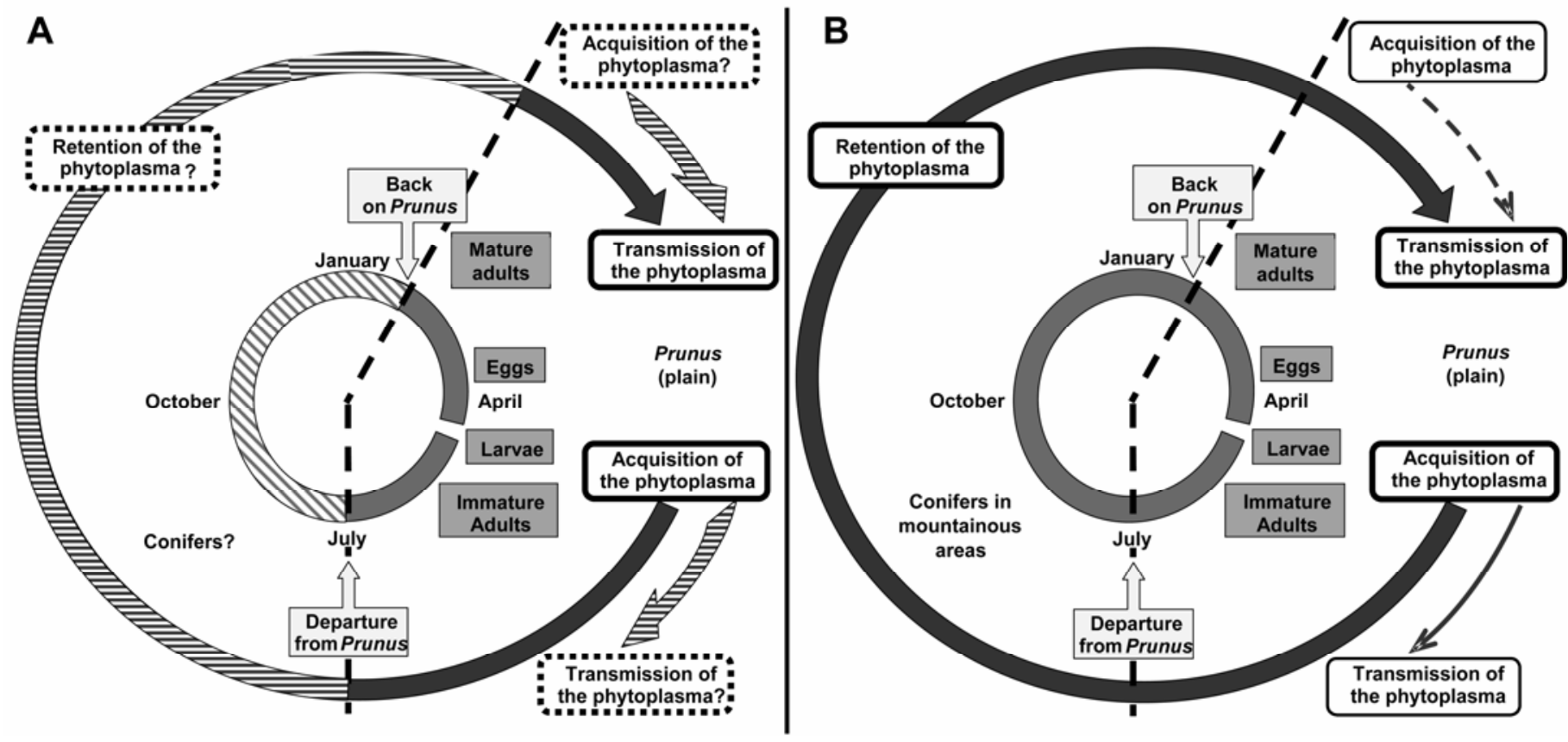

Fig. 7. Summary of Cacopsylla pruni life cycle (inner circle) and transmission cycle (outer circle). Comparison between A, initial questions and B, direct evidence from this study. Striped and dashed arrows and dotted frames correspond to suspected processes. 
phytoplasma, which is consistent with previous results (7). The significant difference in phytoplasma load between immature and mature vectors observed after a 20-day AAP may be caused by a slower phytoplasma multiplication in mature vectors. A previous study on ' $C a$. P. prunorum' showed that, after an initial latency, $C$. pruni is infectious until its death (7); through quantifying ' $C a$. P. prunorum' in $C$. pruni, we demonstrated that ' $C a$. P. prunorum' multiplies in both mature and immature insects and, therefore, is transmitted in a persistent-propagative manner. However, the short-term transmission rate by mature and immature insects remained very low $(0.6 \%)$.

To explain this low transmission rate, it has been hypothesized that a number of immature insects complete the latency on the secondary host (6). Here, we provided three lines of evidence supporting this hypothesis. First, only the few vectors that survived 85 days on Prunus spp. in laboratory conditions could reach the phytoplasma load observed in overwintering adults (and, in nature, most of them would have migrated to conifers before reaching such high values). Second, the proportion of infectious control mature adults (coming from natural populations and, as such, only partly exposed to the phytoplasma when they were immature) was the same as in the group of immature insects fully exposed to the phytoplasma in controlled conditions (Fig. 3B, inset). A third and more direct demonstration is that the transmission rate for adults born on ESFY-infected plants is strikingly higher after overwintering than before; thus, the vast majority of ESFY-positive immature insects are not infectious before migrating from Prunus spp. to conifers. As a result, the mean latency is much longer than the minimum latency of 2 to 3 weeks established previously on 500 immature $C$. pruni (7); in fact, minimum values are almost uninformative (if not misleading) on the median values of the corresponding variables. Previous studies had convincingly suggested that mature adults could conserve the phytoplasma acquired in the previous year, based on phytoplasma detection in the first mature adults appearing in the orchards at the end of winter $(6,7)$, or in mature adults collected on conifers in winter $(11,44)$. Our work provides direct proofs of phytoplasma retention and infectivity after the 8 months spent by the vector on conifers: once exposed to the phytoplasma, $C$. pruni is an efficient vector, but only the following year. After spending several weeks on conifers, most exposed C. pruni probably excrete enough phytoplasma in their saliva to be infectious, thereby ending the latency as defined by Nault (29). However, under this mechanistic definition, latency might be impossible to measure because no Prunus spp. can be inoculated at that time. Instead, we use a definition of more direct epidemiological relevance (referred to as the "effective latency" below): the delay between pathogen acquisition and first inoculation by an individual vector in field conditions. The 8-month-long effective latency reported here is, to our knowledge, unprecedented for any vector-borne disease; it is more than three times higher than the maximum values for other phytoplasmas (17) and for viruses (30).

There is some heterogeneity within the species $C$. pruni regarding phytoplasma-vector interactions, with vectors being in majority "competent", sporadically "hypercompetent" (right tail in Fig. $6 \mathrm{~A}$ ), and "resistant" for $\approx 20 \%$ of the vectors (Figs. 3A and 6). This heterogeneity may have a genetic basis, with important epidemiological consequences if competent and resistant insects also differ in their geographic range or biology.

Epidemiological consequences. Combining the results on ' $\mathrm{Ca}$. P. prunorum' transmission and on $C$. pruni life cycle suggests that ESFY is likely spread according to the following scenario: immature $C$. pruni acquire ' $C a$. P. prunorum' while feeding on an infected Prunus sp. (wild or cultivated) and migrate soon after onto conifers located in mountainous regions; $C$. pruni stays there for 8 months, during which ' $\mathrm{Ca}$. P. prunorum' has enough time to multiply and colonize the salivary glands; at the end of winter, $C$. pruni migrates back to the plains to reproduce on Prunus spp., and infects susceptible plants while feeding. In this scenario, host alternation involves two long-distance migrations between acquisition and inoculation, leading to long-distance dissemination of the disease. This aspect of ESFY transmission cycle has two major epidemiological implications. First, it means that ESFY is essentially a monocyclic disease, with the annual rate of increase in a given orchard depending on the product between the total number of trees in the orchard fed upon by all the mature $C$. pruni and the proportion of infectious vectors in the regional population. Second, long-distance dissemination implies that the proportion of infectious vectors depends on the relative contribution of wild and domesticated Prunus species to the regional pool of infectious $C$. pruni; their relative contribution is itself determined by their relative abundance, infection frequency, infectivity, and host value for $C$. pruni.

These two points affect the potential effectiveness of different disease management strategies. The first point implies that the same effectiveness can be achieved through reducing by a similar proportion either vector density or vector mobility or the proportion of infectious vectors. The second point implies that regional disease management strategies implemented at a scale matching the scale of vector dispersion should take into account the wild reservoirs of ' $C a$. P. prunorum' and C. pruni: P. spinosa, P. domestica, and $P$. cerasifera (4). Where these wild hosts are a significant source of infectious vectors, any control strategy coordinated at a regional scale is likely to be inefficient (e.g., removing the source trees in all the orchards), unreasonable (e.g., removing wild source trees), or unpredictable (e.g., biological control of natural $C$. pruni populations); however, where wild Prunus species play a negligible role in the pathosystem, the regional control of immature $C$. pruni in the infected orchards should efficiently reduce the number of infectious vectors, as should the widespread removal of infected cultivated trees. Paradoxically, control methods focused on the orchard scale are more likely to bear fruit regardless of the role of wild Prunus species; in principle, disease incidence can be lowered through reducing either vector infectivity, the density of mature $C$. pruni, or the number of trees visited by each vector. The best way to reduce vector infectivity in the orchard would be to plant less-susceptible trees. When this is not an option, chemical (or microbiological) control of mature $C$. pruni should enable limiting both vector density and the number of trees fed upon by each vector; vector density should also decrease through a reduction in orchard attractiveness to $C$. pruni (e.g., cutting shoots of the attractive myrobalan or plum rootstocks).

General insights into phytoplasma-vector-plant pathosystems. To what extent are our results generic or completely specific to ESFY in southern France? First of all, the entomological records on $C$. pruni across Europe are fully consistent with the demonstrated life cycle (including host alternation). In addition, $C$. pruni preference for overwintering at altitude has also been reported in Italy (32) and the Czech Republic (11), where ESFY is thus expected to spread at a regional scale. However, in northern Europe, there is no mention that $C$. pruni favors overwintering sites located at higher altitude; therefore, this feature might be an adaptation to warmer summers, increasing survival until the next breeding season through a reduction in the number of degree-days. If host alternation happens between closely located Prunus spp. and conifers, the disease should spread locally; more generally, local secondary spread of the disease might occur where different environmental conditions prevail.

The findings of this study also shed light on the transmission of the Apple proliferation (AP) phytoplasma. Like C. pruni, the psyllid vectors of AP (C. melanoneura and $C$. picta) are univoltine, overwinter on alternative hosts (conifers, for $C$. melanoneura), and spend only a small fraction of their life on their cultivated host (31). Moreover, both AP vectors have low transmission rates in experimental conditions, and the proportion of infectious 
insects is higher among mature adults without controlled acquisition than among immature insects with controlled acquisition $(35,37)$. Thus, AP and ESFY vectors have similar biological cycles and transmission features. These two pathosystems are also closely related in evolutionary terms: AP and ESFY phytoplasmas belong to the same clade (16SrX) within the genus 'Candidatus Phytoplasma', their vectors belong to the same genus (Cacopsylla), and their host plants belong to the same family (Rosaceae). Because of this evolutionary and biological proximity, we hypothesize that AP and ESFY transmission cycles are identical (long effective latency included); other examples of this original transmission cycle may exist among the univoltine psyllid species overwintering as adults on alternative hosts (generally conifers), which represent a third of the species listed in Hodkinson and White (16).

Finally, this pathosystem raises puzzling evolutionary questions. 'Ca. P. prunorum' would have an obvious selective advantage if a full transmission cycle could be completed within each period spent by $C$. pruni on Prunus spp. So, why has ' $C a$. P. prunorum' life history not evolved toward a faster multiplication and translocation within the vector, which would lead to shortterm transmission? One hypothesis is that there may be a trade-off between intra- and interannual transmission resulting from a trade-off between pathogen growth rate and vector longevity and fecundity (14). If short-term transmission could only be increased at the expense of a decrease in $C$. pruni longevity, the infected vectors would die before migrating back to Prunus spp., reducing both vector population size and interannual transmission by mature adults; thus, the cost would likely overcome the benefit, which may explain the observed 8-month-long effective latency. Indeed, a formal study of the evolutionary epidemiology of this pathosystem would be interesting.

\section{ACKNOWLEDGMENTS}

We thank S. Duriez for her help with the initial work on transmission rates, and we are also grateful to S. Dallot, D. Haydon, V. Marie-Jeanne, J.-L. Nottéghem, and M. Peterschmitt for their critical review of this manuscript. The $C$. pruni overwintering experiment was undertaken in collaboration with the Office national des forets (ONF) and Parc national des Cévennes. This work was partly founded by the PSDR program (INRA/Région Languedoc-Roussillon) and by the AIP EpiEmerge (INRA).

\section{LITERATURE CITED}

1. Blaker, H. 2000. Confidence curves and improved exact confidence intervals for discrete distributions. Can. J. Stat. 28:783-798.

2. Breslow, N. E. 1984. Extra-Poisson variation in log-linear models. J. R. Stat. Soc. C 33:38-44.

3. Campbell, C. L., and Madden, L. V. 1990. Introduction to Plant Disease Epidemiology. Wiley, New York.

4. Carraro, L., Ferrini, F., Ermacora, P., and Loi, N. 2002. Role of wild Prunus species in the epidemiology of European stone fruit yellows. Plant Pathol. 51:513-517.

5. Carraro, L., Ferrini, F., Ermacora, P., and Loi, N. 2004. Transmission of European stone fruit yellows phytoplasma to Prunus species by using vector and graft transmission. Acta Hortic. 657:449-453.

6. Carraro, L., Ferrini, F., Labonne, G., Ermacora, P., and Loi, N. 2004. Seasonal infectivity of Cacopsylla pruni, vector of European stone fruit yellows phytoplasma. Ann. Appl. Biol. 144:191-195.

7. Carraro, L., Loi, N., and Ermacora, P. 2001. Transmission characteristics of the European stone fruit yellows phytoplasma and its vector Cacopsylla pruni. Eur. J. Plant Pathol. 107:695-700.

8. Carraro, L., Osler, R., Loi, N., Ermacora, P., and Refatti, E. 1998. Transmission of European stone fruit yellows phytoplasma by Cacopsylla pruni. J. Plant Pathol. 80:233-239.

9. Chabrolin, C. 1924. Quelques maladies des arbres fruitiers de la vallée du Rhône. Ann. Epiphyties 10:263-338.

10. Delic, D., Martini, M., Ermacora, P., Carraro, L., and Myrta, A. 2005. First report of fruit tree phytoplasmas and their psyllid vectors in Bosnia and Herzegovina. J. Plant Pathol. 87:149-150.

11. Fialová, R., Navrátil, M., Lauterer, P., and Navrkalová, V. 2007.
'Candidatus Phytoplasma prunorum': The phytoplasma infection of Cacopsylla pruni from apricot orchards and from overwintering habitats in Moravia (Czech Republic). Bull. Insectol. 60:183-184.

12. Fialová, R., Navrátil, M., Válová, P., Lauterer, P., Kocourek, F., and Poncarová-Vorácková, Z. 2004. Epidemiology of European stone fruit yellows phytoplasma in the Czech Republic. Acta Hortic. 657:483-487.

13. Fisher, R. A. 1935. The logic of inductive inference. J. R. Stat. Soc. A 98:39-54.

14. Galvani, A. P. 2003. Epidemiology meets evolutionary ecology. Trends Ecol. Evol. 18:132-139.

15. Gibson, G. J. 1997. Investigating mechanisms of spatiotemporal epidemic spread using stochastic models. Phytopathology 87:139-146.

16. Hodkinson, I. D., and White, I. M. 1979. Homoptera. Psylloidea. Handbooks for the Identification of British Insects vol. II, Part 5(a). Royal Entomological Society of London, London.

17. Hogenhout, S. A., Oshima, K., El-Desouky, A., Kakizawa, S., Kingdom, H. N., and Namba, S. 2008. Phytoplasmas: Bacteria that manipulate plants and insects. Mol. Plant Pathol. 9:403-423.

18. Jarausch, W., Danet, J.-L., Labonne, G., Dosba, F., Broquaire, J.-M., Saillard, C., and Garnier, M. 2001. Mapping the spread of apricot chlorotic leaf roll (ACLR) in southern France and implication of Cacopsylla pruni as a vector of European stone fruit yellows (ESFY) phytoplasmas. Plant Pathol. 50:782-790.

19. Kison, H., and Seemüller, E. 2001. Differences in strain virulence of the European stone fruit yellows phytoplasma and susceptibility of stone fruit trees on various rootstocks to this pathogen. J. Phytopathol. 149:533-541.

20. Labonne, G., and Lichou, J. 2004. Data on the life cycle of Cacopsylla pruni, Psyllidae vector of European stone fruit yellows (ESFY) phytoplasma, in France. Acta Hortic. 657:465-470.

21. Lauterer, P. 1999. Results of the investigations on Hemiptera in Moravia, made by the Moravian museum (Psylloidea 2). Acta Musei Moraviae Sci. Biol. 84:71-151.

22. Laviña, A., Sabaté, J., García-Chapa, M., Batlle, A., and Torres, E. 2004. Occurrence and epidemiology of European stone fruit yellows phytoplasma in Spain. Acta Hortic. 657:489-494.

23. Lorenz, K.-H., Dosba, F., Poggi Pollini, C., Llácer, G., and Seemüller, E. 1994. Phytoplasma diseases of Prunus species in Europe are caused by genetically similar organisms. Z. Pflanzenkrankh. Pflanzenschutz 101:567-575.

24. Maixner, M., Ahrens, U., and Seemüller, E. 1995. Detection of the German grapevine yellows (Vergilbungskrankheit) MLO in grapevine, alternative hosts and a vector by a specific PCR procedure. Eur. J. Plant Pathol. 101:241-250.

25. Marcone, C., and Seemüller, E. 2001. A chromosome map of the European stone fruit yellows phytoplasma. Microbiology 147:1213-1221.

26. Marzachi, C., Veratti, F., and Bosco, D. 1998. Direct PCR detection of phytoplasmas in experimentally infected insects. Ann. Appl. Biol. 133:4554.

27. Morvan, G. 1977. Apricot chlorotic leaf roll. EPPO Bull. 7:37-55.

28. Morvan, G., Giannotti, J., and Marchoux, G. 1973. Studies on the aetiology of apricot chlorotic leaf roll: Detection of mycoplasmas. Phytopathol. Z. 76:33-38.

29. Nault, L. R. 1997. Arthropod transmission of plant viruses: A new synthesis. Ann. Entomol. Soc. Am. 90:521-541.

30. Nault, L. R., and Ammar, E.-D. 1989. Leafhopper and planthopper transmission of plant viruses. Annu. Rev. Entomol. 34:503-529.

31. Ossiannilsson, F. 1992. The Psylloidea (Homoptera) of Fennoscandia and Denmark. Fauna Entomologica Scandinavica, vol. 26. Brill E. J., Leiden.

32. Poggi Pollini, C., Bissani, R., Giunchedi, L., Mori, N., Dradi, D., and Visigalli, T. 2004. Detection of European stone fruit yellows phytoplasma (ESFYP) in Homoptera insects and in wild stone fruit trees collected in peach orchards in Northern Italy. Acta Hortic. 657:513-518.

33. Ramel, M.-E., Gugerli, P., Bourquin, L., de Meyer, J., and Schaub, L. 2001. Caractérisation de l'enroulement chlorotique de l'abricotier et détection du phytoplasme ESFY en Suisse romande. Rev. Suisse Vitic. Arboric. Hortic. 33:279-286.

34. R Development Core Team. 2004. R: A Language and Environment for Statistical Computing. R Foundation for Statistical Computing, Vienna.

35. Seemüller, E., Dickler, E., Berwarth, C., and Jelkmann, W. 2004. Occurrence of Psyllids in apple orchards and transmission of apple proliferation by Cacopsylla picta (syn. C. costalis) in Germany. Acta Hortic. 657:533-537.

36. Seemüller, E., and Schneider, B. 2004. 'Candidatus Phytoplasma mali', 'Candidatus Phytoplasma pyri' and 'Candidatus phytoplasma prunorum', the causal agents of apple proliferation, pear decline and European stone fruit yellows, respectively. Int. J. Syst. Evol. Microbiol. 54:1217-1226.

37. Tedeschi, R., and Alma, A. 2004. Transmission of apple proliferation phytoplasma by Cacopsylla melanoneura (Homoptera: Psyllidae). J. Econ. Entomol. 97:8-13.

38. Thébaud, G. 2005. Studying the spatio-temporal spread of a vector-borne 
disease by the integration of statistical modelling and experimentation: The case of ESFY (European stone fruit yellows). Ph.D. dissertation, Ecole Nationale Supérieure Agronomique de Montpellier, France.

39. Thébaud, G., Peyrard, N., Dallot, S., Calonnec, A., and Labonne, G. 2005. Investigating disease spread between two assessment dates with permutation tests on a lattice. Phytopathology 95:1453-1461.

40. Thébaud, G., Sauvion, N., Chadœuf, J., Dufils, A., and Labonne, G. 2006. Identifying risk factors for European stone fruit yellows from a survey. Phytopathology 96:890-899.

41. Thompson, J. D., Higgins, D. G., and Gibson, T. J. 1994. Clustal W:
Improving the sensitivity of progressive multiple sequence alignment through sequence weighting, position-specific gap penalties and weight matrix choice. Nucleic Acids Res. 22:4673-4680.

42. van der Plank, J. E. 1963. Plant Diseases: Epidemics and Control. Academic Press, New York.

43. Williams, D. A. 1982. Extra-binomial variation in logistic linear models. Appl. Stat. 31:144-148.

44. Yvon, M., Labonne, G., and Thébaud, G. 2004. Survival of European stone fruit yellows phytoplasma outside fruit crop production areas: A case study in southeastern France. Acta Hortic. 657:477-481.

\section{Erratum}

Corrections were made to the first paragraph on page 267 of this article on March 6, 2009. The plant pathogen 'Candidatus Phytoplasma prunorum' was replaced with the probe $\mathrm{CPp}$. 